\title{
The Pragmatics of English-Persian Dictionaries: Problems and Solutions
}

\author{
Zohreh Gharaei (Corresponding author) \\ M.A. in Translation Studies \\ Faculty of Foreign Languages, Department of English, University of Isfahan \\ Postal Code: 8174674331, Isfahan, Iran \\ E-mail: zohreh.2003@yahoo.com
}

Abbas Eslamirasek

Assistant Professor of Applied Linguistics

Faculty of Foreign Languages, Department of English, University of Isfahan

Isfahan, Iran

E-mail: abbasseslamirasekh@yahoo.com

Received: June 3, 2011 Accepted: June 26, $2011 \quad$ doi:10.5539/ijel.v1n2p83

\begin{abstract}
Inspired by one of the most important contributions modern linguistics has made toward lexicography, the present study is an attempt to investigate the practice of the three most frequently used English-Persian dictionaries in incorporating pragmatic information. To this end, 101 pragmatically marked English words were randomly selected and the treatment of the bilingual dictionaries toward them was closely examined. The study revealed that although labeling is the most frequently used policy, it is still far from desirable as a strategy. The deficiencies can be attributed to the inadequate rate of labeling and inaccuracy and inconsistency in the use of labels. Besides, the study suggests incorporating pragmatic information in the translation equivalents through reducing the number of them to the ones which are good representatives of the specifications of the English word both semantically and pragmatically. Finally, as pragmatic translation equivalents can not be always established, the use of other strategies such as pragmatic examples and usage notes are also suggested.
\end{abstract}

Keywords: English-Persian lexicography, Pragmatic peculiarities, Labeling, Translation equivalent, Exemplification, Usage notes

\section{Introduction}

Bilingual dictionaries can be regarded as bridges connecting speakers of two different linguistic societies. For a bilingual dictionary to successfully fulfill its role in intercultural communications it is necessary to not only take semantic considerations into account, but also pay special attention to the pragmatic specifications of the lemmas. The reason lies in the fact that inappropriate use of language which results in communication failure mostly happens between people of different cultural backgrounds with different conceptual assumptions who speak different languages. Such people are doubtlessly the intended users of bilingual dictionaries. The question is how to define pragmatics and how to integrate it into the task of lexicography.

Apreseyan (1988, in Burkhanov, 2003) believes that pragmatic specifications are those dealing with the speaker's attitude to reality, the message and the interlocutor. Landau (1989: 174-5) stating that pragmatics concerns with usage of the lemmas, believes that it can cover the study of the uses of language including spoken or written, standard as opposed to non-standard as well as the restrictions imposed on the use of language, for instance time, place or social restrictions. He classifies information of this kind into nine categories of currency, frequency of use, geographical variations, specialized terminology, restricted and taboo usage, register and stylistic features, offensive items, slang words, and finally those lemmas loaded with social status like non-standards, sub-standard and illiterate varieties. According to him, one way of incorporating information of this ilk into dictionaries is labeling. Kipfer (1984: 41) who defines pragmatics as variations in language, temporal and spatial features and the relationship between addresser and addressee also believes that this kind of lexicographic information is presented in the form of usage labels. Like Landau and Kipfer, Svensén (1993: 4-6) believes that data of this kind are mostly 
represented by field and register labels. Yong and Peng (2007) confirming the vital role of pragmatics in learner dictionaries as well as general purpose dictionaries, especially bilingual ones, believe that providing the entries in dictionary with an accurate, consistent labeling system for the words with register and stylistic restrictions can be a good way for integrating the achievements of pragmatics into the task of lexicography in general, and bilingual lexicography in particular.

Although labeling as a way of presenting pragmatic information in dictionaries has received a lot of attention among scholars, it is not the only way. Burkhanov (2003) believes that furnishing pragmatic specifications as a prerogative of usage labels is an oversimplification, as such information can be found in any part of entry. Qualifications in definitions or translation equivalents, for instance, can be regarded as one way of representing pragmatic peculiarities (Creamer, 1987; Drysdale, 1987; Zgusta, 1988; Landau, 1989; Atkins, 1995; Burkhanov, 2003). Exemplification is also "an implicit technique of furnishing pragmatic information" (Burkhanov, 2003). Yong \& Peng (2007: 158) regard stylistic and pragmatic function of examples as one of their major roles, especially in bilingual dictionaries due to the users' look-up needs. In their opinion, glosses can also have the same role (Yong \& Peng, 2007: 164). Finally, usage notes have been claimed to be appropriate means of illuminating pragmatic specifications (Landau, 1989: 175; Yong \& Peng, 2007).

Bilingual dictionaries, due to the important role they have in intercultural communication, have been advised to take pragmatic considerations seriously. However, in spite of the vital role they have in production, comprehension and translation related purposes, English-Persian dictionaries still suffer from major deficiencies (Qaneifard, 2003; Ahmadian \& Askari, 2008). Qaneifard (2003) rightly attributes the problems to a number of reasons, among which one can refer to unfamiliarity of the lexicographers with modern approaches to lexicography as well as the lack of any systematic, scientific and realistic criticism about the existing dictionaries. He believes that as far as criticism is concerned, no one has attempted to bring the quality of bilingual dictionaries under close examination. Whatever exists is nothing but some unrealistic praises about the quality of the dictionaries, ignoring all the weaknesses, and if any criticism with a focus on the deficiencies could be found, it is either subjective or so general that is far from constructive. As a result, the only work the researchers can refer to focusing on the quality assessment of bilingual English-Persian dictionaries is that of Ahmadian and Askari (2008). They have mentioned some of the deficiencies existing in these dictionaries very generally and briefly. The dictionaries they analyzed are "the four popular English-Persian dictionaries," as they put, namely: Aryanpur (1998), Bateni (1990), Jaafari (2004), and Haghshenas (2002). The study is mainly a contrastive one, putting the mentioned dictionaries against one another, and focusing on their shortcomings in three areas of (1) choice of Persian equivalents; (2) use of abbreviations, and finally (3) pronunciations. Then, for each category one or two examples are mentioned to show the failure of the dictionaries in providing the users with sufficient information. Finally, the treatment of the four dictionaries regarding the chosen word is discussed.

Due to the scarcity of researches done to bring English-Persian or Persian-English dictionaries under close investigation, no work could be found studying these dictionaries from a pragmatic perspective. The present study makes an attempt to investigate if English-Persian dictionaries have integrated pragmatic information into them, and if so, how such incorporation has been fulfilled and how successful they have been in so doing. To be more specific, the following research questions are to be answered in this study:

(1) What are the practices of English-Persian dictionaries in dealing with pragmatic specifications of English lemmas? Are they systematic enough to be called strategies?

(2) How successful have they been in applying those strategies?

(3) What are the policy implications of this study?

\section{Method}

To choose the English-Persian dictionaries, a simple questionnaire was employed, asking 208 B.A. EFL students about the English-Persian dictionary they used. They were chosen from among English students due to their frequent look-up needs. The views collected revealed that Aryanpur was the most frequently used dictionary among English students. Hezaareh and Farhang Moaaser -e-Pouya turned out to be the second and third frequently used dictionaries, respectively.

In dealing with pragmatic specifications, the researcher made use of the six-partite classification proposed by Yong and Peng (2007: 156). In this classification words with style and register restrictions are grouped as follows: words that (1) are limited to a particular region; (2) have come to English from a foreign origin but still not naturalized; (3) have special meanings when used in special fields or subjects; (4) are confined to a certain time period; (5) can suggest a particular attitude or evoke a particular reaction or feeling on the part of the users; and finally (6) have other restricted uses like the ones used in certain dialects, non-standard speech or special social groups. Considering some of the shortcomings of our dictionaries and due to some practicality reasons, some modifications in the above classification were made. For one thing, we excluded the second category from our 
study because it was difficult for us, non-native English speakers, to decide which word has been naturalized in English and which has not, as our only frame of reference has been monolingual trusted English-English dictionaries. These dictionaries, at times, provide us with the origin of some words coming into English from other languages like Latin or French, but do not give any information regarding their naturality in English. Another modification made was combining the fifth and sixth categories into one category as there is sometimes no clear cut distinction between the words of these two categories. With these modifications, we came up with four categories as explained below.

Regionalism is the first category of the sampled words, referring to geographical restrictions. It can include both national varieties and regional dialects within a national variety (Jackson, 2002). This category consists of 26 randomly selected words: 10 Briticisms, 10 Americanisms, 3 Australianism and 3 Scottish English word. Such proportion is due to the fact that the rate of inclusion of Briticisms and Americanisms in English-English learner dictionaries is much higher than other regionalisms used in other varieties of English (Buzon, 1979; Grenon-Nyenhuis, 2000; Xu, 2008), and this is also true about bilingual English-Persian dictionaries, as their frame of reference is usually monolingual English-English dictionaries. Other varieties such as Irish English or Indian English are rarely treated in English-Persian dictionaries, if treated at all.

The second category of the sampled words consists of those items restricted to specialized fields. To examine the treatment of these bilingual dictionaries with the words restricted to a special field or subject, 10 words were randomly selected.

10 old-fashioned words were selected to give rise to the third category. Mention should be made that in this study no distinction is made between old use and old-fashioned words, while in the trusted monolingual English-English dictionaries such a distinction is marked. For example, $O A L D$ (2000) defines and labels old-fashioned items as those which "are passing out of current use." However, it defines and labels old-use expressions as the ones which "are no longer in current use." The reason for the overlook in this study is that the distinction between these two subcategories is to some extent vague in the bilingual English-Persian dictionaries. In fact, except for Aryanpur, other dictionaries do not draw the distinction at all. Besides, neologisms were excluded from the study, because paying attention to the date of the last edition of the chosen English-Persian dictionaries, we could not expect those words to be included among the words listed in them.

The fourth category was divided into six subcategories consisting of a total of 55 words including 15 formal, 15 informal, 10 literary, five slang, five taboo, and finally five humorous words. Mention should be made that the sampled words were all selected from $O A L D$, and then were double-checked in $L D C E$ to make sure about their pragmatic peculiarities.

After establishing the lexical sample, the treatment of the three bilingual dictionaries in handling the pragmatic features of the words was examined. The purposes were to investigate (1) the strategies these dictionaries employed to show the markedness of the sample, and (2) whether the strategies were successful in reflecting those peculiarities. To reach these ends the frequency of use of each strategy in the three dictionaries, as well as the number of words left unmarked were counted to see how far they are behind the required standards. As translation equivalent by itself is claimed to be one strategy to show the markednees of vocabulary items (Burkhanov, 2003) and in the sample there were a good number of items left with only translation equivalent, it was necessary to see if the Persian equivalents offered are capable of reflecting the pragmatic peculiarities of the head words. As a result, the translation equivalents were also closely examined to see if they are good representatives of the English items, as far as pragmatic peculiarities are concerned.

With regard to the items accompanied with example, the example was examined to see if it was illustrative enough to show the peculiarity of the head word.

\section{Results and discussion}

The results of the analysis of the sampled words indicated four patterns employed by English-Persian dictionaries in dealing with items having pragmatic restriction: (1) the mere translation equivalent; (2) labeling; (3) exemplification; and finally (4) usage notes.

\subsection{Translation equivalent}

As it is indicated by Table 1, English-Persian dictionaries have a strong tendency to rely only on translation equivalents - while the words under question have pragmatic peculiarities - without employing any other strategies, such as labeling, exemplification and usage notes. Table 1 shows the number of cases in which dictionaries have provided the users with only translation equivalents. This pattern is the most frequently observed one in Aryanpur and Pouya. In Hezaareh, it is the second frequently used pattern, however. 85 out of 101 sampled words are depicted using this pattern in Pouya. Aryanpur and Hezaareh use it for 54 and 31 items, respectively. 
As it is evident, these dictionaries in many cases have refrained from using any strategies other than translation equivalent. The lack of widely accepted strategies such as labeling, exemplification and usage notes might only be partially justified in case the translation equivalent itself is expressive of the pragmatic load existing in the English word. A closer look at the translation equivalents offered for the sampled words revealed that in most of the cases translation equivalent on its own is not a good representative of the pragmatic peculiarities of the source words in question. The reason for such a claim can be attributed to two factors:

1. in some cases the negligence of the lexicographers in offering a translation equivalent with a pragmatic specification more or less like that of the English word has caused the juxtaposition of a number of translation equivalents which are in contrast with both one another as well as the English word, as far as pragmatic peculiarities are concerned;

2. in other cases it is not possible to find a translation equivalent in the target language having all implications existing in the source word.

With regard to the first reason, some clarifications and examples seem to be to the point here. Among the sampled words examined, there are a good number of translation equivalents which can be served as evidence for the claim maid above. For instance, Aryanpur has a tendency to use archaic Persian equivalents for English lemmas which

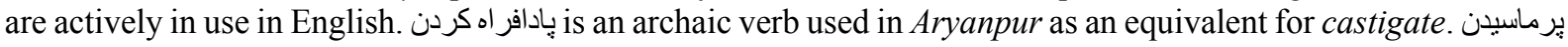
and بساويدن are also offered as equivalents for the technical word palpate, which are both archaic. برديرن for deathtrap, and زرخريد for thrall are two more examples. Moreover, there are some other cases in which register and stylistic features of the Persian equivalents offered, are in contrast with both one another and the English word. A case in point is the equivalents of war-paint as a humorous word. The three equivalents in Aryanpur are and جهره آرايى, the first word is regarded as an archaic word, not in use in present Persian frequently, the second word as an informal word and the third one as a formal word.

Although Hezaareh and Pouya seem to be more careful with this regard, a few cases of deviation can be detected there as well. As an example, one can refer to the definitions offered for the word carouse, a literary word, in Hezaareh. Hezaareh offers four equivalents for it: شادخوارى كردن، ميكسارى كردن، عرق خوارى كردن، باده نوشى كردن

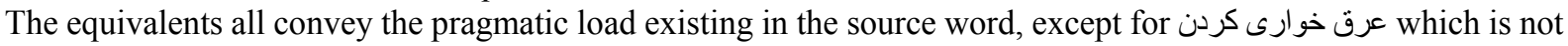
literary at all. Finally, simian can be regarded as a case of deviation in Pouya. One of the equivalents offered in this dictionary is من عich is not a technical word at all; instead it is regarded as offensive in present Persian. Generally, avoidance of offering a variety of equivalents, each with a different style and register, can be a key to success in reflecting the pragmatics of the words, doubtlessly.

As for the second reason, it should be explained that lexical adjustment is believed to be at work at different levels: semantic level, grammatical level, pragmatic level and sociolinguistic level (Samei, 2000). Many words in any two languages might be claimed to be equivalents as far as one or two of these levels are concerned, but total equivalence can not be achieved without considering all four levels. Some factors such as setting, topic of discussion, the relation between addresser and addressee are all among determining variables leading to different varieties such as formal, informal, literary, offensive, disapproving and humorous. With regard to sociolinguistic level, different dialects, the currency of the words and the social connotations the words convey are the implications a word might carry. In the majority of cases, it is impossible to find translation equivalents reflecting all these peculiarities as there is not one hundred percent overlapping between languages.

A closer look at the sampled words of the present study reveals that in some cases it is very difficult to find pragmatically appropriate equivalents, if possible at all. Aureole, incorrigible, palpate, sputum, boor, ere, and simpleton are some examples which can show the challenges a lexicographer might face while trying to find Persian equivalents which are appropriate from a pragmatic view.

Whatever the reason of such failure might be, the partial solution for such shortcomings and challenges can be achieved by:

1. being more sensitive to the choice of pragmatic translation equivalents, and omitting those equivalents which are not appropriate as far as pragmatic and sociolinguistic levels are concerned;

2. employing other strategies such as labeling, exemplification and making use of usage notes, especially in the case of those lemmas for which it is difficult to offer pragmatic translation equivalents due to the lack of overlap between languages.

\subsection{Labeling}

Labeling has been regarded as one of the widely used, strongly suggested strategies employed by lexicographers to show pragmatic peculiarities of the source words (Kipfer, 1984; Zgusta, 1988; Apresyan, 1988; Sevensén, 1993; Jackson, 2002; Yong \& Peng, 2007). Providing the users with an appropriate labeling system which reveals the register and stylistic specifications of the source words is an inherent part of each lexicographer's task. Such 
labeling system is required to be accurate and consistent (Yong \& Peng, 2007). Despite the pivotal role an appropriate labeling system can serve in dictionaries, the present study revealed that English-Persian dictionaries suffer from some obvious shortcomings, which can be largely attributed to two sources: insufficient labels and inappropriate labels.

\subsubsection{Insufficiency}

Insufficiency refers to the low rate of labeling in English-Persian dictionaries. The three dictionaries under study vary in labeling rate, and Hezaareh outperforms the other two, in this respect. Anyway, there are a significant number of pragmatically restricted English words left without any labels in the three dictionaries. Table 2 indicates that among 101 sampled words of this study, Aryanpur, Hezaareh and Pouya mark 45, 70, and 16 items with labels and leave 56, 31 and 85 items unlabeled, respectively.

\subsubsection{Inappropriateness}

Inappropriateness is the second source of deficiency in labeling systems of the dictionaries under investigation, which encompasses two factors of accuracy and consistency for the purpose of this study. Accuracy can be defined as the degree to which the label attributed to a lemma in the English-Persian dictionaries matches well to the pragmatic peculiarity of the lemma in question, and consistency means whether all the lemmas which share the same pragmatic restriction are marked with the same label throughout the whole English-Persian dictionaries. A case of inaccuracy is the practice of Hezaareh in labeling informal, slang and taboo words. Hezaareh does not distinguish between these three categories as far as labeling is concerned, and uses عاميا in order to mark most of them. To have a more accurate labeling system, it is suggested to assign different labels to lemmas having the three above mentioned restrictions so that the users can distinguish between the register and stylistic variations of these categories, since the implications of an informal word are totally different from those of a taboo word. As a result, using the same labels for marking them causes misunderstanding and subsequently misuse on the part of the users. To solve the problem, in addition to عاميانه, labels like زنتنه an can be used. Besides, it is advised to introduce the labels used in the body of dictionaries in the front matter, and define them. That way, the users can make a better use and have a better understanding of the implications of labels.

The cases of inconsistency are also evident in the three dictionaries. For example in Aryanpur خودمانى is used to label some of the slang words like dude, while for crappy the label has been shifted into ji The labels assigned to taboo words are another case of inconsistency in this dictionary. Nigger and yid, both are taboo words while the former is marked as تحقبر آميز and the latter is marked as زننده. To address this problem, the lexicographers are advised to adopt a consistent labeling system, introduce it in the front matter and use it consistently throughout the whole book.

\subsection{Exemplification}

Examples in dictionaries are to fulfill a variety of functions including semantic, grammatical, collocational and pragmatic functions. The latter is the focus of this section. Examples can show the appropriate use of the source words, its degree of formality and its affective implications by providing the users with the context of use of the source word (Yong \& Peng, 2007). The fact that an adequate dictionary must provide the lemma with its stylistic values, its degree of formality and its affective implications through appropriate examples shows the importance of the pragmatic role examples play. Such a role seems to be very vital in bilingual dictionaries because "non-native speakers will expect examples to help them to understand not only the meaning of the lexical item but also its use" (Yong \& Peng, 2007). Such examples are called pragmatic examples for the purpose of this study. In spite of the role of examples in shedding light on the pragmatic peculiarities of the source words, only six examples could be found for the 101 sampled words of this study, among which four belong to Aryanpur. Hezaareh and Pouya each have on example. Table 3 shows the examples given in these two dictionaries.

The six examples listed in the table, can hardly reflect the pragmatic features of the English words. The first example shows occur which is a formal word in a sentence. Although the example fulfills the grammatical function by using the past form of the verb, it carries no pragmatic value, as it does not hold any clues to the formality of the source word. It is also true about the second example; although it fulfills the collocational function, it does not show the formality of tumult. Example three can be regarded as a successful one which reflects the formality of the English word. In example four, the occurrence of the word with the contraction of the subject and the verb provides some clues to the informality of the word. The fifth and sixth examples are not large enough to cover the technicality of the English lemmas. In Table 4, occur, tumult, abrasion and velocity are used in sentences which have some clues to the pragmatic peculiarities of them.

\subsection{Usage notes}

Hezaareh, as its front matter claims, seems to be the only dictionary providing the users with some usage notes, illustrating and comparing the pragmatic features of lemmas which are considered to be synonyms. A case in point 
is the formal word occur which is of course accompanied with a label. The usage note in this case, juxtaposes the words occur, happen and crop up distinguishing them from one another as far as levels of formality and their uses are concerned.

Despite the fact that the function of usage notes is "mainly to deal with pragmatically sensitive words and expressions" (Yong \& Peng, 2007: 56), Aryanpur and Pouya do not use them at all.

\section{Conclusion}

This article examined the practice of the most frequently used English-Persian dictionaries in dealing with pragmatically restricted English items. It was found that although strategies such as pragmatic translation equivalent, labeling, exemplification and usage notes could be found in these dictionaries, none of them are employed neither adequately nor appropriately. As a result, a more systematic approach is advised to be taken by the lexicographers to improve the quality of the bilingual dictionaries, as far as pragmatic considerations are concerned. Reducing the number of translation equivalents to those which are better representatives of the lemma, not only semantically, but also pragmatically and avoiding the juxtaposition of a succession of pragmatically irrelevant translation equivalents -as it is the practice of Aryanpur- have been proved to add to the success of the offered translation equivalents. Moreover, as one hundred overlap between any two languages is impossible in many cases, the notion of complete equivalent has been called into question. As a result, lexicographers are advised to make a more sufficient and active use of other complementary strategies such as labeling, exemplifications and usage notes.

\section{References}

Ahmadian, M. \& Askari, H. (2008). A contrastive Analysis of English-Persian Dictionaries. Translation Studies, 22(2), 5-22.

Aryanpur Kashani. M. (1999). The Aryanpur Prigressive English-Persian Dictionary. Tehran: Computer World Co. (Aryanpur).

Atkins, B. T. S. (1995). The Role of the Example in a Frame Semantics Dictionary, in Shibatani M. \& Thompson S. A. (eds.). Essays in Semantics and Pragmatics. Amsterdam: John Benjamin Publishing Company, 25-42.

Bateni. M. R. (2006). The Living English-Persian Dictionary. Tehran: Farhang Moaser Publishers. (Pouya).

Burkhanov, I. (2003). Pragmatic Specifications: Usage Indications, Labels, Examples; Dictionaries of Style, Dictionaries of Collocations, in Sterkenburg P. (ed.), A Practical Guide to Lexicography. Amsterdam: John Benjamin Publishing Company.

Cowie, A. P. (1989). The Language of Examples in English Learner Dictionaries, in James G. (ed.), Lexicographers and Their Works. Exeter: University of Exeter Press, 55-65.

Creamer, T. (1987). Beyond the Definition: Some Problems with Examples in Recent Chinese- English and English-Chinese Bilingual Dictionaries, in Cowie A. (ed.), The Dictionary and the Language Learner:Papers from the EUROLEX Seminar at the University of Leeds, 1-3 April 1985, 238-245. Tübingen: Max Niemeyer Verlag.

Drysdale, P. D. (1987). The Role of Examples in Learners' Dictionary, in Cowie A. (ed.), The Dictionary and the Language Learner: Papers from the EUROLEX Seminar at the University of Leeds, 1-3 April 1985, 213-223. Tübingen: Max Niemeyer Verlag.

Grenon-Nyenhuis, C. (2000). The Dictionary as a Cultural Institution. International Communication Studies. 10(1), 159-166. [Online] available: www.uri.edu/iaics/.../14\%20Chantale\%20Grenon-Nyenhuis.pdf.

Haghshenas, A. M. Samei, H. \& Entekhabi, N. (2003). One Volume Millennium English-Persian Dictionary. Tehran: Farhang Moaser Publishers. (Hezaareh).

Jackson, H. (2002). Lexicography: An Introduction. London \& New York: Routledge.

Kipfer, B. (1984). Workbook on Lexicography: A Course for Dictionary Users. Exeter: University of Exeter.

Landau, S. I. (2001). Dictionaries: the Art and Craft of Lexicography. Cambridge: Cambridge University Press.

Qaneifard, A. (2003). The Challenges of Lexicography in Iran. Translation Studies, 1(1), 31-42.

Samei, H. (2000). Bilingual dictionaries: introductory principles. One Volume Millennium English-Persian Dictionary. Tehran: Farhang Moaser Publishers.

Summers, D. (2003). Longman Dictionary of Contemporary English. London: Pearson Education Ltd.

Wehmeier, S. (2000). Oxford Advanced Learner's Dictionary. Oxford: Oxford University Press. 
Xu, H. (2008). Exemplification Policy in English Learners' Dictionaries. International Journal of Lexicography, 21(4), 395-417. doi:10.1093/ijl/ecn015, http://dx.doi.org/10.1093/ijl/ecn015

Yong, H. Peng, J. (2007). Bilingual Lexicography from a Communicative Perspective. Amsterdam: John Benjamin Publishing Company.

Zgusta, L. (1988). Pragmatics, Lexicography and Dictionaries of English. World Englishes. 7(3), 243-253. doi:10.1111/j.1467-971X.1988.tb00235.x, http://dx.doi.org/10.1111/j.1467-971X.1988.tb00235.x

Table 1. Words with translation equivalent only

\begin{tabular}{|l|l|l|}
\hline Dictionary & Frequency & Percentage \\
\hline Aryanpur & 54 & $54.45 \%$ \\
Hezaareh & 31 & $30.69 \%$ \\
Pouya & 85 & $84.15 \%$ \\
\hline
\end{tabular}

Table 2. Words marked with labels

\begin{tabular}{|l|l|l|l|}
\hline Dictionary & Frequency & Percentage & Rank \\
\hline Aryanpur & 45 & $44.55 \%$ & 2 \\
Hezaareh & 70 & $69.3 \%$ & 1 \\
Pouya & 16 & $15.84 \%$ & 3 \\
\hline
\end{tabular}

Table 3. Exemplified English words

\begin{tabular}{|c|c|c|c|c|}
\hline No. & $\begin{array}{l}\text { English } \\
\text { words }\end{array}$ & $\begin{array}{c}\text { Prgmatic } \\
\text { peculiarity }\end{array}$ & Dictionary & Example \\
\hline 1 & occur & formal & Aryanpur & 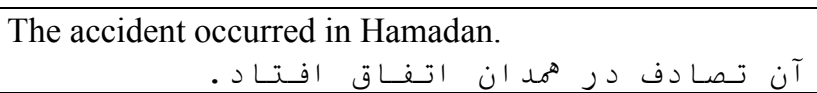 \\
\hline 2 & tumult & formal & Pouya & 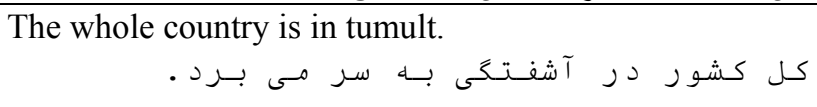 \\
\hline 3 & undue & formal & Aryanpur & 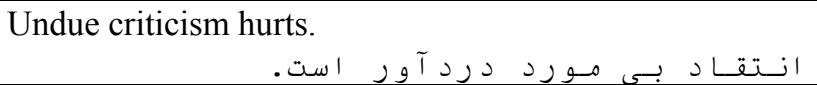 \\
\hline 4 & famished & informal & Hezaareh & 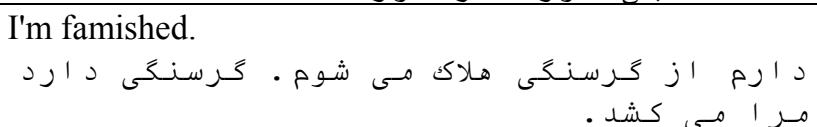 \\
\hline 5 & abrasion & technical & Aryanpur & خـر اش يــوست \\
\hline 6 & velocity & technical & Aryanpur & the velocity of the light \\
\hline
\end{tabular}

Table 4. Possible pragmatic examples

\begin{tabular}{|c|c|c|c|}
\hline No. & $\begin{array}{c}\text { English } \\
\text { words }\end{array}$ & $\begin{array}{l}\text { Pragmatic } \\
\text { peculiarity }\end{array}$ & Suggested Example \\
\hline 1 & occur & formal & 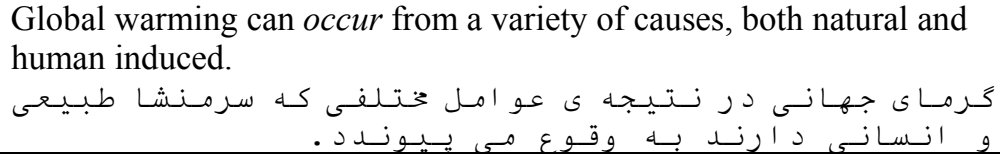 \\
\hline 2 & tumult & formal & 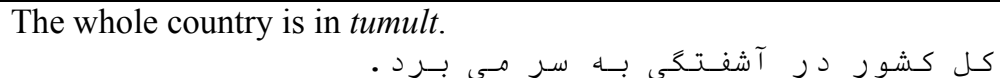 \\
\hline 3 & abrasion & technical & 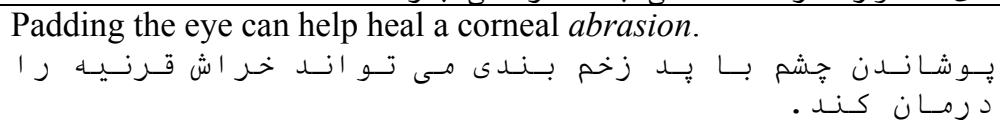 \\
\hline 4 & velocity & technical & 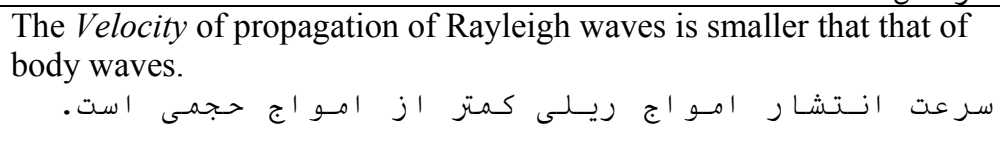 \\
\hline
\end{tabular}




\section{Appendix}

\section{Sampled words}

\begin{tabular}{|l|l|l|}
\hline Category & Subcategory & Sampled words \\
\hline $\begin{array}{l}\text { Words marked with special } \\
\text { style \& register }\end{array}$ & Fml & $\begin{array}{l}\text { abate, altercation, await, castigate, defray, elapse, } \\
\text { gratuity, lineage obsequies, occur, probity, relinquish, } \\
\text { torpor, tumult, undue } \\
\text { beefy, bombshell, brainy, confab, deathtrap, famished, } \\
\text { goofy, jittery, lifer, nab, rattler, saggy, snooze, teaser, zit }\end{array}$ \\
Lit & $\begin{array}{l}\text { Slgame, aureole, bower, carouse, dell, limpid, quest, } \\
\text { ravening, thrall, wellspring }\end{array}$ \\
Tab & $\begin{array}{l}\text { Hum } \\
\text { bollocks, crappy, dude, fag, knockers } \\
\text { cunt, nigger, shit, turd, yid } \\
\text { hirsute, impecunious, incorrigible, warpaint, yonkel }\end{array}$ \\
\hline Technical & - & $\begin{array}{l}\text { abrasion, igneous, liquidity, palpate, simian, sputum, } \\
\text { surety, torque, velocity }\end{array}$ \\
\hline Old-fashioned & $\begin{array}{l}\text { aviator, boor, damsel, ere, gentry, manservant, } \\
\text { perchance, simpleton, vamp, whence }\end{array}$ \\
\hline Regionalisms & $\begin{array}{l}\text { abseil, barmy, cheeky, dicky, don, hoick, invigilate, } \\
\text { question master, quid, suss } \\
\text { absentee ballot, baby carriage, demagogue, flunk, } \\
\text { knobbly, rappel, schlep, snow job, valediction }\end{array}$ \\
AmE & Scot & $\begin{array}{l}\text { cobber, pom (pommy), Sheila } \\
\text { bairn, kirk, sassenach }\end{array}$ \\
\hline
\end{tabular}

